\title{
COMUNICAÇÃOCIENTÍFICA
}

\section{FORMAÇÃO DE MUDAS DE JABUTICABEIRA (Plinia sp.) EM DIFERENTES SUBSTRATOS E TAMANHOS DE RECIPIENTES ${ }^{1}$}

\author{
MOESES ANDRIGO DANNER ${ }^{2}$, IDEMIR CITADIN ${ }^{3}$, ALCENIR DEAMORIM FERNANDES JUNIOR ${ }^{2}$, \\ ANDRÉ PAULO ASSMANN ${ }^{4}$, SÉRGIO MIGUEL MAZARO 5 , SIMONE APARECIDAZOLET SASSO 4
}

RESUMO - O trabalho foi desenvolvido na Universidade Tecnológica Federal do Paraná (UTFPR), Câmpus Pato Branco - PR, de abril de 2005 a abril de 2006, com o objetivo de avaliar diferentes substratos (Plantmax ${ }^{\circledR}$ Hortaliças; terra de mata nativa + vermicomposto $(1: 1 \mathrm{v} / \mathrm{v})$; terra de mata nativa + areia granulação média + vermicomposto $(1: 1: 1 \mathrm{v} / \mathrm{v})$; terra de mata nativa + vermiculita + vermicomposto $(1: 1: 1 \mathrm{v} / \mathrm{v})$; e vermicomposto) e tamanhos de recipiente $\left(577 \mathrm{~cm}^{3}\right.$ e $\left.1.963,5 \mathrm{~cm}^{3}\right)$ sobre a emergência de sementes e a formação de mudas de jabuticabeira. Foram avaliados o percentual de emergência e o Índice de Velocidade de Emergência (IVE) aos 3 meses após a semeadura. Aos 12 meses após a semeadura, foram efetuadas as avaliações de altura da planta, diâmetro do caule e área foliar, matéria seca de raiz e da parte aérea das mudas. Os substratos Plantmax ${ }^{\circledR}$ Hortaliças e a mistura de terra de mata nativa + vermicomposto (1:1 v/v) no recipiente com volume de $1.963,5 \mathrm{~cm}^{3}$, proporcionam melhor crescimento das mudas de jabuticabeira.

Termos para indexação: Myrtaceae, propagação sexuada, produção de mudas, substratos, sementes.

\section{SEEDLING DEVELOPMENT OF JABUTICABA FRUIT TREES (Plinia sp.) IN DIFFERENT SUBSTRATES AND SIZES OF CONTAINERS}

\begin{abstract}
The experiment was carried out at UTFPR, Campus Pato Branco, from april 2005 to april 2006 with the aim of testing different substrates (Plantmax ${ }^{\circledR}$ Hortaliças; soil of the native wood + vermicompost $(1: 1 \mathrm{v} / \mathrm{v})$; soil of the native wood + medium sand + vermicompost $(1: 1: 1 \mathrm{v} / \mathrm{v})$; soil of the native wood + vermiculite + vermicompost $(1: 1: 1 \mathrm{v} / \mathrm{v})$; and vermicompost $)$ and different volume of containers $\left(577 \mathrm{~cm}^{3}\right.$ e 1963,5 $\left.\mathrm{cm}^{3}\right)$ on the seed emergence and formation of 'jabuticaba' fruit tree seedlings. The percentage of emergence was evaluated and it was realized the calculation of EVI (Emergence Velocity Index) ninety days after seed germination. Twelve months after seed germination it was evaluated the seedling height, diameter of stem and foliar area, dry matter of the roots and the canopy. The results showed that the substrate Plantmax ${ }^{\circledR}$ Hortaliças in the two recipients and the substrate $1 / 2$ soil of the native wood $+1 / 2$ vermicompost in the biggest recipient $\left(1963,5 \mathrm{~cm}^{3}\right)$ presented the best development of the 'jabuticaba' fruit tree seedlings. Index terms: Myrtaceae, sexual propagation, plants propagation, substrate, seeds.
\end{abstract}

Dentre as espécies nativas de importância regional no Sul do Brasil, destaca-se a jabuticabeira (Plinia sp.), pertencente à família Myrtaceae. Sua fruta é muito apreciada, tanto para consumo natural como para a fabricação de geléias, vinhos e licores caseiros.

Houve uma alteração nomenclatural do gênero Myrciaria (Berg, 1857) para o gênero Plinia, a qual foi proposta por Sobral (1985). Este autor afirma que sementes com cotilédones separados são uma característica constante em Plinia e muito rara em Myrciaria, que tem os cotilédones, na maior parte das vezes, soldados. Da mesma forma, o mesmo autor relata que inflorescências congestas e caulifloras, entre outras, são características do gênero Plinia. Porém, o gênero Myrciaria é ainda largamente empregado no meio científico e pode ser considerado como sinonímia do gênero Plinia.

São conhecidas em torno de nove espécies de jabuticabeira (Mattos, 1978), porém ainda existe dúvida se a espécie de jabuticabeira de ocorrência natural na região Sudoeste do Paraná é P. cauliflora ou P. trunciflora, objeto de investigação a posteriori.

Mesmo considerando os avanços no processo de propagação assexuada, o principal método de propagação da jabuticabeira ainda é por sementes, por ser uma espécie de difícil enraizamento (Manica, 2000), e também devido ao desconhecimento, por parte dos produtores, das técnicas de alporquia e enxertia. $\mathrm{O}$ uso de sementes justifica-se também no processo de obtenção de porta-enxertos, no melhoramento genético e na manutenção da variabilidade.

Apesar disso, as informações existentes na literatura sobre germinação de sementes e formação de mudas de jabuticabeira são escassas. Há referências sobre a influência da temperatura, luz, umidade e maturação dos frutos na germinação (Valio \& Ferreira, 1992; Andrade \& Martins, 2003; Alexandre et al., 2004), porém apenas um trabalho foi encontrado sobre a influência do substrato utilizado, no qual se compararam areia e vermiculita (Alexandre et al., 2004), e nenhum trabalho sobre a

(Trabalho 125-2006). Recebido em 24-08-2006. Aceito para publicação em 14-02-2007). Trabalho executado com auxílio financeiro do CNPq,

Edital CT-Agro 022/2004, processo n. 50.6741/2004-04.

2 Acadêmico de Agronomia. UTFPR. Bolsista do CNPq/PIBIC. UTFPR, Câmpus Pato Branco. moesesandrigo@yahoo.com.br

${ }^{3}$ Eng $^{\circ}$. Agr ${ }^{\circ}$. Dr. em Agronomia. Prof. UTFPR. PR 469. Km 01. 85501 - 970. Tel. (46) 32202609. Pato Branco. idemir@utfpr.edu.br

${ }^{4}$ Acadêmico de Agronomia - UTFPR, Câmpus Pato Branco, Estagiário. andrebaliza@yahoo.com.br

${ }^{5}$ Eng. Agr. MSc, Prof. UTFPR Câmpus Dois Vizinhos. Estrada Boa Esperança, 85560-000, sergio@utfpr.edu.br 
influência do tamanho da embalagem na qualidade das mudas formadas.

Um fator determinante na porcentagem final de germinação e emergência de sementes e da formação das mudas é o substrato utilizado, sendo que a estrutura, aeração, capacidade de retenção de água, $\mathrm{pH}$, riqueza em nutrientes essenciais e grau de infestação de patógenos são características que podem variar conforme o tipo de material utilizado (Popinigis, 1977). Outro aspecto a ser considerado é o grau de dificuldade na obtenção, formulação e no custo do substrato. Normalmente, os substratos comercializados apresentam características físicoquímicas adequadas à formação inicial de diversas espécies, porém o alto custo pode inviabilizar a produção. Por isso, há a necessidade de se adaptar um substrato composto por materiais facilmente obtidos, com características químicas, físicas, biológicas e econômicas desejáveis.

Assim como o substrato, o tamanho do recipiente também exerce influência sobre o crescimento de mudas, sendo que os recipientes de maior volume proporcionam melhor crescimento do sistema radicular das mesmas (Mendonça et al., 2003).

O objetivo deste trabalho foi avaliar o efeito de diferentes substratos e tamanhos de recipiente sobre a emergência das sementes e a formação de mudas de jabuticabeira.

Os frutos foram coletados em abril de 2005 em pomar doméstico situado no município de Pato Branco-PR. Após a extração, as sementes foram despolpadas com cal virgem, lavadas, secas à sombra, selecionadas as de maior tamanho e então semeadas nos diferentes substratos e embalagens, a uma profundidade de aproximadamente $1 \mathrm{~cm}$, na mesma data da coleta. O experimento foi conduzido em casa de vegetação, na UTFPR Câmpus Pato Branco, em delineamento inteiramente casualizado, em esquema fatorial $5 \times 2$ (substratos $\mathrm{x}$ tamanho do recipiente), com quatro repetições e três unidades de observação por repetição. Os substratos utilizados foram (A - Plantmax ${ }^{\circledR}$ Hortaliças; B - terra de mata nativa + vermicomposto $(1: 1 \mathrm{v} / \mathrm{v})$; C - terra de mata nativa + vermicomposto + areia granulação média $(1: 1: 1 \mathrm{v} / \mathrm{v}) ; \mathrm{D}$ - terra de mata nativa + vermicomposto + vermiculita $(1: 1: 1 \mathrm{v} / \mathrm{v}) ; \mathrm{E}$ - vermicomposto). Os tamanhos de recipiente foram de $577 \mathrm{~cm}^{3}$ (7 cm de diâmetro x $15 \mathrm{~cm}$ de altura x $0,006 \mathrm{~cm}$ de espessura, respectivamente) e $1.963,5 \mathrm{~cm}^{3}(10 \mathrm{~cm}$ de diâmetro $\mathrm{x}$ $25 \mathrm{~cm}$ de altura x $0,006 \mathrm{~cm}$ de espessura, respectivamente), sendo utilizados como recipientes sacos de polietileno de coloração preta.
Realizou-se análise química de todos os substratos e componentes utilizados nas misturas, no laboratório de solos da UTFPR, Câmpus Pato Branco, sendo estes dados mostrados na Tabela 1.

Durante o processo de formação da muda não foi realizado nenhum tipo de complemento nutricional.

Procedeu-se à análise do percentual de emergência e do índice de velocidade de emergência (IVE) aos três meses após a semeadura. O IVE foi calculado segundo Popinigis (1977), sendo determinado pela divisão do número de plântulas emergidas pelo número de dias transcorridos da data de semeadura. O total desses valores somados foi considerado o índice de velocidade de emergência.

Doze meses após a semeadura, foram realizadas medições da altura das plantas, com régua graduada $\mathrm{em} \mathrm{cm}$; diâmetro do colo, com paquímetro digital; área foliar, com o aparelho LI-COR (modelo LI-3100), e matéria seca de raiz e parte aérea das mudas, medida em balança digital após secagem em estufa a $60^{\circ} \mathrm{C}$, por sete dias, no Laboratório de Fisiologia Vegetal da UTFPR, Câmpus Pato Branco.

Os dados foram submetidos à análise de variância, e as médias foram comparadas pelo teste Tukey $(\mathrm{P} \leq 0,05)$. Apenas os dados de IVE foram transformados à raiz quadrada de $\mathrm{x}+0,5$. A emergência das sementes de jabuticabeira teve início aos 30 dias após a semeadura, e aos 3 meses, obteve-se um percentual médio de emergência de 80,8 \%, sendo superior àquela observada por Alexandre et al. (2004) e por Andrade \& Martins (2003), que obtiveram germinação inferior a $77 \%$, demonstrando que as condições fornecidas para emergência de plantas no presente trabalho foram adequadas. Para esta característica, não se observou influência significativas dos diferentes tratamentos, demonstrando que todos os substratos utilizados, bem como os diferentes tamanhos de recipiente foram adequados para o processo de germinação e emergência das sementes.

O IVE foi influenciado somente pelos diferentes substratos, com maior valor para o substrato $\mathrm{A}(1,31)$, diferindo significativamente somente do substrato $\mathrm{C}$, que obteve um IVE de 0,77 (Figura 1). Isto significa que, no substrato $C$, as plântulas podem tornar-se mais vulneráveis às condições adversas do meio, por emergirem mais lentamente e passarem mais tempo nos estádios iniciais de crescimento (Martins et al., 1999). Provavelmente, isto ocorreu porque o substrato C continha areia, que possui menor capacidade de retenção de umidade.

TABELA 1 - Composição química dos substratos e componentes das misturas utilizadas no estudo. UTFPR, Câmpus Pato Branco, 2006.

\begin{tabular}{|c|c|c|c|c|c|c|c|c|c|c|c|c|}
\hline Substratos & pH & Al & $\mathbf{C a}$ & $\mathrm{Mg}$ & $\mathbf{H}+\mathbf{A l}$ & $\mathbf{P}$ & $\mathbf{K}$ & M.O. & $\mathbf{m}$ & $\mathbf{V}$ & SB & $\mathbf{t}$ \\
\hline & $\mathrm{CaCl}_{2}$ & \multicolumn{4}{|c|}{$\mathrm{cmol}_{(\mathrm{c})} \mathrm{dm}^{3}$} & \multicolumn{2}{|c|}{$\mathrm{mg} \mathrm{dm}{ }^{3}$} & \multicolumn{3}{|c|}{$\%$} & \multicolumn{2}{|c|}{$\mathrm{cmol}_{(\mathrm{c})} \mathrm{dm}^{3}$} \\
\hline Plantmax ${ }^{\circledR}$ Hortaliças & 5,1 & 0,1 & 14,94 & 12,14 & 6,53 & 311,3 & 762,45 & 13 & 0,31 & 81,64 & 29,03 & 35,56 \\
\hline Areia & 4,7 & 0,02 & 0,52 & 0,28 & 1,89 & 8,52 & 11,73 & 0,4 & 2,35 & 30,51 & 0,83 & 2,72 \\
\hline Vermicomposto & 5,9 & 0 & 14,3 & 11,95 & 3,52 & 311,82 & $1.485,8$ & 10,72 & 0 & 89,5 & 30 & 33,57 \\
\hline Terra de mata nativa & 4 & 2,95 & 1 & 1,2 & 18,82 & 3,59 & 156,4 & 6,7 & 53,15 & 12,14 & 2,6 & 21,42 \\
\hline Vermiculita & 7,5 & 0 & 2,93 & 45,23 & 1,62 & 15,57 & 168,13 & 0,4 & 0 & 96,77 & 48,59 & 50,21 \\
\hline
\end{tabular}

M.O. - Matéria orgânica; SB - soma de bases; t - CTC efetiva; m - saturação de Al; T - CTC a pH 7,0; V - saturação de bases. 


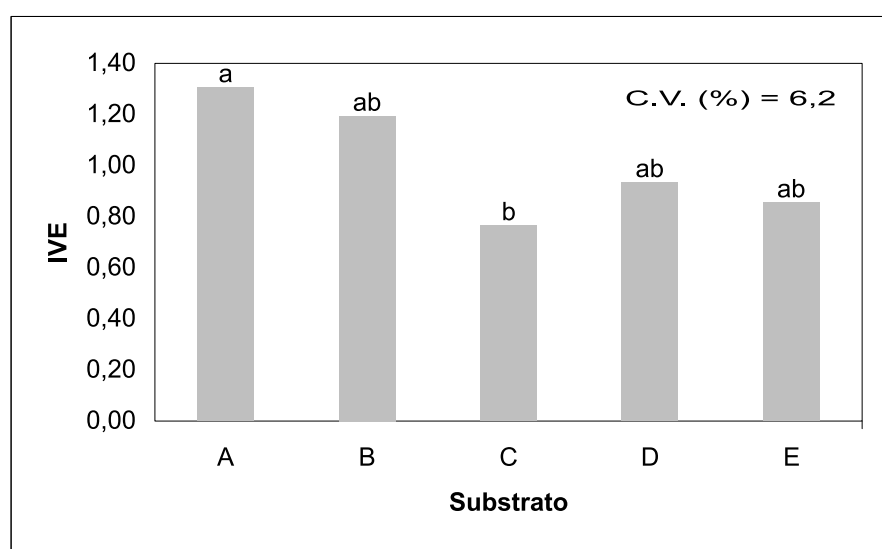

FIGURA 1 - Índice de velocidade de emergência (IVE) de plântulas de jabuticabeira em função de substratos. Médias seguidas de mesma letra não diferem entre si, pelo teste de Tukey $(\mathrm{P} \leq 0,05)$. UTFPR, Câmpus Pato Branco, 2006. Substrato A (Plantmax ${ }^{\circledR}$ Hortaliças); substrato B (terra de mata nativa + vermicomposto $1: 1 \mathrm{v} / \mathrm{v}$ ); substrato $\mathrm{C}$ (terra de mata nativa + areia granulação média + vermicomposto $1: 1: 1 \mathrm{v} / \mathrm{v}$ ); substrato $\mathrm{D}$ (terra de mata nativa + vermiculita + vermicomposto $1: 1: 1$ $\mathrm{v} / \mathrm{v}$ ); e substrato $\mathrm{E}$ (vermicomposto).

Alexandre et al. (2004) obtiveram IVE de 2,17 no substrato vermiculita, avaliado 36 dias após a semeadura, que diferiu significativamente do substrato areia, com IVE de 0,94 , devido à maior capacidade de retenção de umidade da vermiculita.

Para que ocorra a germinação e emergência, as sementes não necessitam de nutrientes, mas apenas de hidratação e aeração para que se procedam as reações que induzam à formação do caulículo e da radícula, sendo que uma boa porosidade do substrato permite o movimento de água e de ar, favorecendo a germinação de forma mais rápida (Simão, 1971).

Houve interação entre os diferentes tipos de substratos e tamanho de recipientes para as características altura da muda, diâmetro do caule, área foliar e matéria seca de raiz e parte aérea (Tabela 2).

Para altura da muda, quando se utilizou o substrato A, não houve influência significativa do tamanho do recipiente. Porém, quando se utilizaram os demais substratos, o recipiente maior (recipiente 2) proporcionou maior crescimento das mudas. Quanto ao diâmetro do caule, observou-se, em todos os substratos, com exceção do substrato $\mathrm{C}$, que o recipiente de maior tamanho proporcionou maior diâmetro. Para essa variável, não se observou diferença significativa entre substratos quando utilizado o recipiente menor. Porém, quando se utilizou o recipiente maior, o substrato $\mathrm{C}$ proporcionou o menor desenvolvimento do diâmetro do caule.

As mudas que se desenvolveram no recipiente maior apresentaram maior acúmulo de matéria seca da parte aérea e maior área foliar, independentemente do substrato utilizado, quando comparado com as mudas desenvolvidas no recipiente 1 , com menor volume de substrato $\left(577 \mathrm{~cm}^{3}\right)$. Para ambas as características, no recipiente com menor volume, o melhor substrato foi o A, que diferiu significativamente dos demais. $\mathrm{O}$
TABELA 2 - Altura da muda, diâmetro do caule, área foliar, matéria seca da raiz e da parte aérea de mudas de jabuticabeira em função de substratos e tamanhos de recipiente. UTFPR, Câmpus Pato Branco, 2006.

\begin{tabular}{|c|c|c|c|}
\hline Susbtrato** & Recipiente $1 * * *$ & Recipiente 2 & Média de substrato \\
\hline \multicolumn{4}{|c|}{ Altura da muda (cm) } \\
\hline $\mathbf{A}$ & $23,38 \mathrm{Aa}^{*}$ & $24,00 \mathrm{ABa}$ & $23,69 \mathrm{~A}$ \\
\hline B & $19,42 \mathrm{Bb}$ & $26,33 \mathrm{Aa}$ & $22,87 \mathrm{~A}$ \\
\hline $\mathrm{C}$ & $16,38 \mathrm{Bb}$ & $21,27 \mathrm{Ba}$ & $18,82 \mathrm{~B}$ \\
\hline D & $19,01 \mathrm{Bb}$ & $24,06 \mathrm{ABa}$ & $21,53 \mathrm{~A}$ \\
\hline E & $17,42 \mathrm{Bb}$ & $26,75 \mathrm{Aa}$ & $22,09 \mathrm{~A}$ \\
\hline Média de recipiente & $19,12 \mathrm{~b}$ & $24,48 \mathrm{a}$ & C.V. $(\%)=6,9$ \\
\hline \multicolumn{4}{|c|}{ Diâmetro do caule (mm) } \\
\hline $\mathbf{A}$ & $4,31 \mathrm{Ab}$ & $5,37 \mathrm{Aa}$ & $4,84 \mathrm{~A}$ \\
\hline B & $4,01 \mathrm{Ab}$ & 5,33 Aa & $4,67 \mathrm{~A}$ \\
\hline $\mathrm{C}$ & 3,74 Aa & $3,83 \mathrm{Ba}$ & $3,78 \mathrm{~B}$ \\
\hline D & $4,21 \mathrm{Ab}$ & $5,67 \mathrm{Aa}$ & 4,94 A \\
\hline $\mathbf{E}$ & $3,70 \mathrm{Ab}$ & $5,94 \mathrm{Aa}$ & $4,82 \mathrm{~A}$ \\
\hline Média de recipiente & $3,99 \mathrm{~b}$ & $5,23 \mathrm{a}$ & C.V. $(\%)=6,6$ \\
\hline \multicolumn{4}{|c|}{ Área foliar $\left(\mathrm{cm}^{2}\right)$} \\
\hline A & $318,43 \mathrm{Ab}$ & $343,48 \mathrm{Aa}$ & $330,96 \mathrm{~A}$ \\
\hline B & $224,34 \mathrm{Bb}$ & $359,97 \mathrm{Aa}$ & 292,16 B \\
\hline $\mathbf{C}$ & $157,51 \mathrm{Db}$ & $196,36 \mathrm{Da}$ & $176,94 \mathrm{D}$ \\
\hline D & $189,96 \mathrm{Cb}$ & $261,52 \mathrm{Ca}$ & $225,74 \mathrm{C}$ \\
\hline $\mathbf{E}$ & $115,31 \mathrm{~Eb}$ & $295,13 \mathrm{Ba}$ & $205,22 \mathrm{C}$ \\
\hline Média de recipiente & $201,11 \mathrm{~b}$ & $291,29 \mathrm{a}$ & C.V. $(\%)=4,94$ \\
\hline \multicolumn{4}{|c|}{ Matéria seca da raiz $(\mathrm{g})$} \\
\hline A & 1,62 Aa & $1,93 \mathrm{ABa}$ & $1,77 \mathrm{~A}$ \\
\hline B & $0,91 \mathrm{BCb}$ & $2,42 \mathrm{Aa}$ & $1,67 \mathrm{AB}$ \\
\hline C & $0,62 \mathrm{Cb}$ & $2,12 \mathrm{ABa}$ & $1,37 \mathrm{~B}$ \\
\hline D & $1,37 \mathrm{ABa}$ & $1,68 \mathrm{Ba}$ & $1,53 \mathrm{AB}$ \\
\hline $\mathbf{E}$ & $0,88 \mathrm{BCb}$ & $2,11 \mathrm{ABa}$ & $1,49 \mathrm{AB}$ \\
\hline Média de recipiente & $1,08 \mathrm{~b}$ & $2,05 \mathrm{a}$ & C.V. $(\%)=14,3$ \\
\hline \multicolumn{4}{|c|}{ Matéria seca da parte aérea $(\mathrm{g})$} \\
\hline $\mathbf{A}$ & $5,07 \mathrm{Ab}$ & $5,73 \mathrm{Aa}$ & $5,40 \mathrm{~A}$ \\
\hline B & $4,48 \mathrm{Bb}$ & $5,82 \mathrm{Aa}$ & $5,15 \mathrm{~B}$ \\
\hline C & $2,28 \mathrm{Db}$ & $4,88 \mathrm{Ca}$ & $3,58 \mathrm{E}$ \\
\hline D & $4,30 \mathrm{Bb}$ & $5,14 \mathrm{BCa}$ & $4,72 \mathrm{C}$ \\
\hline $\mathbf{E}$ & $2,89 \mathrm{Cb}$ & $5,35 \mathrm{Ba}$ & $4,12 \mathrm{D}$ \\
\hline Média de recipien & $3,80 \mathrm{~b}$ & $5,38 \mathrm{a}$ & C.V. $(\%)=2,8$ \\
\hline
\end{tabular}

*Médias seguidas de mesma letra, maiúscula na coluna e minúscula na linha, não diferem entre si, pelo teste de Tukey $(\mathrm{P} \leq 0,05)$.

** Substrato A (Plantmax ${ }^{\circledast}$ Hortaliças); substrato B (terra de mata nativa + vermicomposto $1: 1 \mathrm{v} / \mathrm{v}$ ); substrato $\mathrm{C}$ (terra de mata nativa + areia granulação média + vermicomposto 1:1:1 v/v); substrato D (terra de mata nativa + vermiculita + vermicomposto 1:1:1 v/v); e substrato E (vermicomposto).

***Recipiente 1: $577 \mathrm{~cm}^{3}$; recipiente 2: $1.963,5 \mathrm{~cm}^{3}$.

substrato $\mathrm{C}$ promoveu o menor desenvolvimento foliar, independentemente do tamanho do recipiente.

Com relação à matéria seca das raízes, observou-se que, para os substratos A e D, não houve influência significativa do tamanho do recipiente. Quando se utilizou o recipiente menor, os melhores substratos foram A e D. No recipiente maior, observase diferença significativa apenas entre o substrato $\mathrm{B}$, com maior desenvolvimento radicular, e o substrato $\mathrm{D}$, com menor desenvolvimento.

Alexandre et al. (2004) observaram efeito do substrato na germinação e no desenvolvimento inicial de mudas de jabuticabeira, sendo que o substrato vermiculita apresentou as maiores médias em todas as variáveis analisadas, em comparação ao substrato areia. 
Quanto aos substratos utilizados no presente trabalho, no recipiente de maior volume, observou-se que não há diferença entre os substratos A e B, sendo que este último tem a vantagem de ser mais econômico. O bom desempenho na formação das mudas obtido por estes substratos pode ser atribuído às suas características físicas e químicas, pois apresentam maior porosidade total, o que proporciona maior capacidade de retenção de água e aeração (Silva et al., 2001; Mendonça et al. 2003) e maior quantidade de nutrientes essenciais às plântulas.

O substrato Plantmax ${ }^{\circledR}$ Hortaliças apresenta teores elevados de nutrientes, principalmente de fósforo, que tem efeito sobre o desenvolvimento da parte aérea das plântulas (Tabela 1). Silva et al. (2001) observaram que o substrato Plantmax ${ }^{\circledR}$ proporcionou maior crescimento de mudas de maracujazeiro azedo em comparação ao substrato vermiculita.

O vermicomposto apresenta alta densidade total, boa retenção de água e teor de húmus altos, tendo seu uso aprovado como condicionador de solo (Kämpf, 2000); além disso, apresenta alta porcentagem de saturação por bases (Tabela 1). A terra de mata nativa apresenta características como alto teor de matéria orgânica e potássio (Tabela 1); além disso, provavelmente, contém uma microbiota ativa dos solos onde a jabuticabeira é nativa. A combinação destes dois componentes originou um substrato favorável para o crescimento e formação de mudas de jabuticabeira. Também Souza et al. (2000), misturando terriço de mata ao solo de cerrado na proporção de 1:1, observaram maior crescimento de plantas de cagaiteira, devido ao maior teor de matéria orgânica e nutrientes do terriço de mata.

Na média, o substrato $\mathrm{C}$ foi inferior aos demais substratos em todas as características avaliadas, exceto quanto à característica de matéria seca das raízes, para a qual diferiu apenas do substrato B. Provavelmente, isto ocorreu devido à utilização de areia nesse substrato, a qual possui menor capacidade de retenção da umidade, o que pode ter prejudicado o crescimento das plântulas. Além disso, a areia possui baixo teor de matéria orgânica e de nutrientes (Tabela 1).

$\mathrm{Na}$ média, o recipiente de maior volume proporcionou melhor desenvolvimento das mudas de jabuticabeira. Isto pode ter ocorrido devido ao maior espaço e disponibilidade de nutrientes, já que, no recipiente menor, os nutrientes são esgotados em pouco tempo, sendo que, durante o processo de formação da muda, não ocorreu complemento nutricional. Resultados semelhantes foram obtidos por Mendonça et al. (2003) com mudas de mamoeiro, no qual o recipiente de maior volume proporcionou o maior crescimento das mudas.

Para a formação de mudas de jabuticabeira com 12 meses, conclui-se que:

1- a utilização de recipiente com capacidade para 1.963,5 $\mathrm{cm}^{3}$, contendo como substrato o Plantmax ${ }^{\circledR}$ Hortaliças ou a mistura de terra de mata nativa + vermicomposto $(1: 1 \mathrm{v} / \mathrm{v})$, possibilita a obtenção de mudas de jabuticabeira com qualidade agronômica superior.

\section{AGRADECIMENTOS}

Ao CNPq, pela concessão da Bolsa de Iniciação Científica e financiamento de projeto através do edital CT-AGRO 022/2004.

\section{REFERÊNCIAS}

ALEXANDRE, R. S.; WAGNER Jr., A.; NEGREIROS, J. R. da S. et al. Efeito do estádio de maturação dos frutos e de substratos na germinação de sementes e desenvolvimento inicial de plântulas de jabuticabeira. In: SIMPÓSIO NACIONAL DO MORANGO, 2.,ENCONTRODEPEQUENASFRUTASEFRUTASNATIVAS DOMERCOSUL, 1., 2004, Pelotas. Resumos... Pelotas: Embrapa Clima Temperado, 2004. p.422-427.

ANDRADE, R. A. de.; MARTINS, A. B. G. Influence of the temperature in germination of seeds of jabuticaba tree. Revista Brasileira de Fruticultura, Jaboticabal, v.25, n.1, p.197-198, 2003.

KÄMPF, A. N. Substrato. In: KÄMPF, A. (Ed.). Produção comercial de plantas ornamentais. Guaíba: Agropecuária, 2000. p.45-88.

MANICA, I. Frutas nativas, silvestres e exóticas 1: técnicas de produção e mercado: abiu, amora-preta, araçá, bacuri, biribá, carambola, cereja-do-rio-grande, jabuticaba. Porto Alegre: Cinco Continentes, 2000. 327p.

MARTINS, C. C.; NAKAGAWA, J.; BOVI, M. L. Efeito da posição da semente no substrato e no crescimento inicial das plântulas de palmito-vermelho (Euterpe espiritosantensis Fernandes - Palmae). Revista Brasileira de Sementes, Brasília, v.21, n.1, p.164-173, 1999.

MATTOS, J. L. R. Frutos indígenas comestíveis do Rio Grande do Sul. Porto Alegre: Secretaria da Agricultura, s.d. 31p. (Publicações \pm PRNR, 1).1978.

MENDONÇA, V.; ARAÚJO NETO, S. E. de; RAMOS, J. D.; PIO, R.; GONTIJO, T. C. A. Diferentes substratos e recipientes na formação de mudas de mamoeiro "Sunrise Solo". Revista Brasileira de Fruticultura, Jaboticabal, v.25, n.1, p. 127130, 2003.

VIEIRA NETO, R. D. Efeito de diferentes substratos na formação de mudas de mangabeira (Hancornia speciosa Gomes). Revista Brasileira de Fruticultura, Cruz das Almas, v.20, n.3, p.265-271, 1998.

POPINIGIS, F. Fisiologia de sementes. Brasília: AGIPLAN, 1977. 289p.

SILVA, R. P. da; PEIXOTO, J. R.; JUNQUEIRA, N. T. V. Influência de diversos substratos no desenvolvimento de mudas de maracujazeiro-azedo (Passiflora edulis Sims f. flavicarpa DEG). Revista Brasileira de Fruticultura, Jaboticabal, v.23, n.2, p.377-381, 2001.

SIMÃO, S. Manual de fruticultura. São Paulo: Ceres, 1971. 530p.

SOBRAL, M. Alterações Nomeclaturais em Plinia (Myrtaceae). Boletim do Museu Botânico de Curitiba, Curitiba, n. 63, p.14, 1985.

SOUZA, E. R. B. de; NAVES, R. V.; CARNEIRO, I. F.; et al. Emergência e crescimento de plantas de cagaita (Eugenia dysenterica DC.) em diferentes substratos. Revista Brasileira de Fruticultura, Jaboticabal, v.22, n.3, p.426-430, 2000.

VALIO, I. F. M.; FERREIRA, Z. de L. Germination of seeds of Myrciaria cauliflora (Mart.) Berg. (Myrtaceae). Revista Brasileira de Fisiologia Vegetal, Lavras, v. 4, n. 2, p. 95-98, 1992. 